Goal setting in teams: Impact of learning and performance goals on process and performance.

Citation:

Nahrgang, J. D., DeRue, D. S., Hollenbeck, J. R., Spitzmuller, M., Jundt, D. K., \& Ilgen, D. R. 2013. Goal setting in teams: Impact of learning and performance goals on process and performance.

Organizational Behavior \& Human Decision Processes, 122: 12-21. 


\begin{abstract}
This study examined the impact of three alternative types of goals (specific learning, general “do your best” learning, and specific performance) on team performance. Eighty four-person teams engaged in an interdependent command and control simulation in which the team goal and task complexity were manipulated. Contrary to research at the individual level, teams with specific learning goals performed worse than did teams with general “do your best” learning goals or specific performance goals. The negative effects of specific learning goals relative to general "do your best” learning goals and specific performance goals were amplified under conditions of increased task complexity and were explained by the amount of coordination in the teams.
\end{abstract}

Keywords: goal-setting; team processes; team performance 
Goal Setting in Teams: The Impact of Learning and Performance Goals on Process and Performance

One of the most established theories of motivation is that of goal setting (Latham, 2007; Latham \& Locke, 2007; Mitchell \& Daniels, 2003), which demonstrates that goals can significantly influence individual and team performance (Kleingeld, van Mierlo, \& Arands, 2011; Locke \& Latham, 1990; O’Leary-Kelly, Martoccio, \& Frink, 1994). Prior research suggests that the effects of goal setting are similar at the individual and team levels of analysis (e.g., Chen, Kanfer, DeShon, Mathieu, \& Kozlowski, 2009; O’Leary-Kelly et al., 1994). Yet, the interconnectedness among team members and the collective nature of team tasks may in fact make the motivational processes associated with goal setting different at the team level than at the individual level (Chen \& Kanfer, 2006; Kozlowski \& Bell, 2003; Latham \& Locke, 2007).

One burgeoning area of research in goal setting at the individual level is the distinction between learning and performance goals (e.g., Cianci, Klein, \& Seijts, 2010; Kozlowski \& Bell, 2006; Seijts, Latham, Tasa, \& Latham, 2004). In response to findings that specific, difficult goals harm learning and skill acquisition, individual-level research suggests that learning goals, rather than performance goals, should be set when tasks are complex or a person lacks the knowledge to perform the task effectively (Seijts et al., 2004). Recent research suggests that individual-level learning goals should be specific and difficult, much like performance goals (Seijts \& Latham, 2005; Seijts et al., 2004). Although research has demonstrated the positive effect of specific, difficult performance goals on team functioning (Kleingeld et al., 2011; O’Leary-Kelly et al., 1994), few studies have examined learning goals in teams (Brown \& Latham, 2002).

We theorize that the effects of specific learning goals observed at the individual level will not generalize to the team level for two reasons. First, we submit that learning and performance goals cue different motivations and behavioral responses. Thus far, research on team goal setting 
has primarily focused on the extent to which performance goals cue responses such as increased effort, planning, and strategy formulation (Weingart, 1992; Weingart \& Weldon, 1991; Weldon, Jehn, \& Pradhan, 1991). Research has yet to investigate the responses cued by learning goals. Second, we expect goal specificity and task complexity to influence how learning goals cue those responses. We theorize that the combination of a learning focus and high specificity will cue team members to adopt a more narrow focus on learning specific aspects of the task and therefore impair team coordination. We also expect task complexity to be an important boundary condition of the goal-performance relationship in teams.

The purpose of this paper is to investigate the extent to which findings regarding specific learning goals at the individual level (Seijts et al., 2004) generalize to the team level, and to understand the mechanism through which goal type (learning, performance) and specificity influence team performance. We propose that specific learning goals are less effective in team contexts than general "do your best” learning goals and specific performance goals, and that these differential effects operate through the process of team coordination. Finally, we expect these differential effects to be further amplified on complex tasks, resulting in a first-stage mediated moderation model (Edwards \& Lambert, 2007).

Theory and Hypotheses

Learning and Performance Goals in Teams: The Role of Team Coordination

Group goals have two important dimensions. The first dimension, goal content, focuses team members on the results being sought (Latham, 2007; Locke \& Latham, 1990). Attention can be shifted to different results based on whether the goal has a learning or a performance focus, and this shift in focus cues different motivations and behavioral responses from team members (DeShon \& Gillespie, 2005; Dweck, 1986; Kozlowski \& Bell, 2006; Seijts et al., 
2004). The second dimension, goal specificity, reduces the interpretive leeway of the exact meaning of the goal (Locke \& Latham, 1990), and thus can also alter behavioral responses.

We posit that the content and specificity of team goals will cue different responses, with a particular focus on how teams coordinate their efforts. Team coordination refers to the management of synchronous activities that align the pace and sequencing of team member's contributions towards goal accomplishment. Team coordination is closely intertwined with the task work of the team, includes both communication and support behaviors within the team, and is more heavily relied on for effective functioning when the interdependence among team members increases (Marks, Mathieu, \& Zaccaro, 2001; Wittenbaum, Vaughan, \& Stasser, 1998). Specific learning goals versus general "do your best” learning goals. When goal content is learning, attention is focused on knowledge or skill acquisition (Seijts \& Latham, 2005). Learning goals focus attention on mastering a task, discovering task-relevant strategies, and achieving learning objectives (DeShon \& Gillespie, 2005; Locke \& Latham, 2002; Seijts \& Latham, 2005; Seijts et al., 2004). Attention is explicitly directed to learning the task, and this learning focus initiates a search process to acquire the knowledge and skills needed to master the task. Team contexts, relative to individual contexts, create an opportunity for team members to distribute their attention, search for information, and pool their collective knowledge via information exchange (Latham \& Locke, 2007). This collective search and information exchange process lies at the core of effective team learning (Edmondson, 1999; Ellis et al., 2003; Gibson \& Vermeulen, 2003). Teams can also build transactive memories in which team members not only build their own knowledge, but also build knowledge about which team members possess other knowledge (e.g., Moreland, 1999) which leads to stronger team processes and performance (DeChurch \& Mesmer-Magnus, 2010). 
Exchanging information and supporting other team members are core aspects of team coordination and a key feature of teams (Marks et al., 2001). We expect teams with learning goals to engage in more team coordination to achieve learning objectives and discover taskrelevant strategies. This increase in team coordination allows team members to master the task, thereby improving team performance. Although a learning goal may focus the attention on learning and cue the need for team coordination, the specificity of the learning goal will be important in determining the level of team coordination. We hypothesize that a specific learning goal, rather than a general learning goal, will lead to lower team coordination and thus, lower team performance. There are two reasons for this hypothesis.

First, a specific learning goal narrows the focus of attention for all team members to learning individual aspects of the task (Rothkopf \& Billington, 1979). Thus, each team member focuses on learning the same set of specific objectives. Team members will also increase their focus on the specific learning objectives in order to reduce the apprehension and distraction which occurs from the mere presence of other team members (Geen, 1989, 1991). Focusing on the narrow set of specific learning objectives makes it likely that there will be less information sharing in the team. Team members will only search for and share insights pertaining to those objectives, and are thus less likely to search for or share additional learning insights that are not specified in the learning goal. Prior research has shown that individuals with specific learning goals learn less about off-task material (Rothkopf \& Billington, 1979). Likewise, focusing on a specific set of learning objectives directs attention away from supporting other team members in mastering the task.

Second, specific learning goals increase team members’ perception of time pressure. Prior research shows that individuals given specific goals perceive greater time pressure than do 
individuals who receive “do your best” goals (Kanfer \& Ackerman, 1989). High specificity in team learning goals may also lead to perceptions of increased time pressure. In team contexts, versus individual contexts, these perceptions of time pressure can lead team members to focus on a restricted range of task-relevant cues (Karau \& Kelly, 1992; Kelly \& Karau, 1999) and limit the degree of information exchange among team members, something that is essential for effective team coordination (Kelly \& Loving, 2004). Likewise, due to perceptions of increased time pressure, attention will be directed to specific learning objectives and away from supporting other team members in mastering the task.

Hypothesis 1: Teams with specific learning goals will have lower team performance relative to teams with general "do your best" learning goals.

Hypothesis 2: The negative effect of specific learning goals on team performance relative to general "do your best" learning goals will be mediated by lower team coordination. Specific learning goals versus specific performance goals. When goal content is performance, attention is focused on demonstrating skill through achieving certain outcomes (DeShon \& Gillespie, 2005; Seijts \& Latham, 2005). Performance goals aim at attaining a standard of task proficiency or achieving a task outcome (Seijts et al, 2004). With performance goals, there is less emphasis on searching for information, because the knowledge and skills needed to achieve the performance goal are generally considered a given. Rather than initiating a search for the knowledge and skills needed to perform the task, performance goals cue behaviors that allow individuals to demonstrate their skills and achieve the desired performance level (Latham \& Locke, 2007). Similar to specific learning goals, we also expect that specific performance goals will narrow team members’ attention to achieving specific standards of team performance. We hypothesize that teams with specific learning goals, relative to teams with 
specific performance goals, will engage in less team coordination, and thus, will have lower team performance. Again, there are two reasons for this hypothesis.

First, each member will focus on the same standard of performance and engage in behaviors that enable the team to achieve the desired outcome. This focus on the standard of performance is likely to be heighted so that team members can again reduce the apprehension and distraction that arises from the mere presence of other team members (Geen, 1989, 1991). We contend that in order to achieve a specific performance goal, team members must exchange task-relevant information and provide mutual support. Second, relative to learning goals, performance goals focus each team member on demonstrating his or her skills, abilities, and competence (DeShon \& Gillespie, 2005; Seijts \& Latham, 2005). Team members can demonstrate their skills to one another by exchanging task-relevant information and supporting other team members. Through the exchange of information, other team members will know whether or not someone understands how to perform the task well. Likewise, if one team member helps others with their work, then that person directly demonstrates that he or she has the skills and abilities to perform well on the task. With learning goals, in contrast, the emphasis is on developing these skills and abilities. Team members with learning goals will focus on developing their skills and abilities rather than demonstrating their competence via information exchange and supporting other team members.

Hypothesis 3: Teams with specific learning goals will have lower team performance relative to teams with specific performance goals.

Hypothesis 4: The negative effect of specific learning goals on team performance relative to specific performance goals will be mediated by lower team coordination. 
We expect that the mediating effect of team coordination will vary depending on team task complexity. We focus on task complexity because complex tasks often increase the demand for information exchange and present teams with unbalanced workloads, both of which can accentuate the importance of coordination processes in the team goal-performance relationship. Task complexity is a function of (a) the number of distinct pieces of information that have to be processed to accomplish the task, (b) the sequencing requirements associated with bringing information and actions together, and (c) the stability of the information processes/actionoutcomes relationship (Wood, 1986). Prior research demonstrates that task complexity moderates the relationship between goals and performance at the individual level, such that the effects of specific, difficult goals on performance are much stronger on simple tasks than they are on complex tasks (Locke \& Latham, 1990; Wood, Mento, \& Locke, 1987). Similarly, task complexity may be a boundary condition for the goal-team performance relationship in team goal setting (Weldon \& Weingart, 1993). We expect task complexity to influence the extent to which team members engage in coordination activities.

In simple task conditions, goals influence performance directly by activating automated strategies and plans, which involve increased effort, persistence, and attention (Latham, 2007; Locke \& Latham, 1990). But when a task becomes more complex, these automated strategies or plans are less effective. This is especially true when changes in complexity influence segments of the task that are accomplished through these automated strategies or plans. On most complex tasks, successful performance relies on the development of more sophisticated strategies (Latham, 2007; Locke \& Latham, 1990; Wood \& Locke, 1990). Team members cannot rely solely on their own individual effort and persistence to reach the team goal in a complex task, but must instead exchange information and support one another in order to achieve the team goal. 
We expect that teams with general “do your best” learning goals are more likely to initiate a search for additional information cues present in a complex task and exchange this information among their members (Gibson \& Vermuelen, 2003). Likewise, the dynamic nature of complex tasks requires team members to further support one another so that team members can master the task. Teams with specific learning goals are less likely to search for additional learning insights due to their narrow focus on specific learning objectives (Rothkopf \& Billington, 1979). This narrow focus will also direct attention away from supporting other team members. We also expect that team members with specific performance goals will exchange task-relevant information and support each other in order to meet the increased information cues and dynamism that occurs in complex tasks. In a complex task, team members with specific learning goals are less likely to coordinate with other members because their focus will be on achieving their specific learning objectives rather than on exchanging task-relevant cues and supporting other team members (Nissen \& Bullemer, 1987).

Hypothesis 5: The negative effect of specific learning goals on team coordination relative to general "do your best" learning goals will be stronger for teams operating in a complex task.

Hypothesis 6: The negative effect of specific learning goals on team coordination relative to specific performance goals will be stronger for teams operating in a complex task.

Method

Participants, Research Design, and Procedures

Three hundred twenty undergraduate students in an upper-level management course at a large Midwestern university were participants for this study. They were randomly assigned to 4- 
person teams ( $N=80$ teams). The average age of the participants was 21 years $(S D=1.9$ years) and 54 percent of the participants were male. With regards to race, 79 percent of the participants were Caucasian, 12 percent were Asian/Pacific Islander, 4 percent were African-American, and the remaining participants were of other races or declined to reveal their race. Participation in the study was voluntary; however, in exchange for their participation, all participants received course credit. In addition, to ensure adequate motivation, all teams were eligible for cash prizes (\$40 per team) on the basis of their goal achievement. Across all three goal conditions, teams were eligible for cash prizes if they achieved the highest level of the goals set for them in their particular goal condition. Teams were not told of differences in goal conditions among teams and were blind to the hypotheses of the study.

The task was a dynamic and networked computer simulation that was a modified version of the Distributed Dynamic Decision-making (DDD) simulation developed for the Department of Defense for research and training (for a detailed description of the simulation, see Hollenbeck et al. 2002). During the task, team members monitored a restricted geographic region for both enemy and friendly forces. Enemy forces should not be allowed to move into the restricted area, but friendly forces could move there. In order to be timely and accurate in disabling forces, team members must differentiate between enemy and friendly forces in order to know which forces to allow into an area (i.e., friendly forces) and which enemy forces to disable (quickly) when reaching the restricted area. Each team member had the option of exchanging information about the identity of the force with other team members. Each team member controlled four types of assets, with varying speed and capabilities to disable enemy forces. An asset that was high on one dimension, like the capability to disable all types of enemy forces, tended to be low on another dimension, like the speed to reach enemy forces. Thus, each asset had its own unique 
advantages and disadvantages and team members needed to differentiate among the capabilities of the assets in order to reach forces in a timely manner and have the capability to disable them if necessary. Because certain assets were slow to reach forces and reset their capability to disable enemy forces, team members needed to use their assets efficiently in order to avoid missing opportunities for monitoring and disabling enemy forces. Each team member was able to engage and disable any enemy that encroached on his/her geographical region and to help other teammates disable enemies in his or her geographical region (see also Beersma et al., 2003 for more details). Team members were in the same room when completing the simulation and thus were able to communicate face-to-face.

Twelve individuals were scheduled for each three hour experimental session. Upon entering the laboratory for their scheduled session, the 12 participants were randomly assigned to a 4-person team. Each team was randomly assigned to a separate room, and within the room, each team member was randomly assigned to a computer station. Training, which was consistent for all teams in the study, included declarative and procedural knowledge regarding the simulation. The entire training period lasted approximately 90 minutes. The first 30 minutes of training were devoted to familiarizing the participants with the simulation and included a video that described the object of the simulation, its scoring, and the capabilities of the assets employed in the simulation. The next 30 minutes of training were devoted to hands-on training, where the trainer explicitly walked the participants through the mechanics of the simulation, including how to launch and move vehicles, identify targets, and disable targets. The final 30 minutes of training allowed the participants to practice in an environment similar to the environment in which they would later perform. After training, the teams were given instructions regarding their 
goals and focus for the upcoming simulation. After the simulation, all participants were debriefed.

\section{Manipulations and Measures}

Goal Conditions. The team goals varied with respect to content (learning versus performance) and specificity (general versus specific). Thus, each team was randomly assigned to one of three goal conditions: specific learning goal, general “do your best” learning goal, and specific performance goal. We did not include a general performance goal condition, given the overwhelming evidence that individuals and teams with specific performance goals outperform those with general performance goals (Kleingeld et al., 2011; Locke \& Latham, 1990; O’LearyKelly et al., 1994). This decision was also consistent with our focus on learning goals and the generalizability of the assertion (at the individual level) that learning goals should be specific, much like performance goals (Seijts \& Latham, 2005; Seijts et al., 2004). By excluding the general performance goal condition, we also increased our statistical power for testing differences among the three goal conditions.

The three goal conditions were dummy coded, with the specific learning goal condition as the reference group. In both the specific learning goal condition and the general "do your best” learning goal condition, teams were instructed to focus on developing new skills and strategies for working on the task. They were also told that the development of knowledge and skills related to the task was valued, expected, and would be rewarded. The content of the learning goals was also differentiated in terms of specificity. In the general "do your best" learning goal condition, teams were told that their team should focus on "doing your best" to learn the task. These instructions were consistent with prior research instructions for general goals (e.g., Seijts et al., 2004). Teams in the specific learning goal condition were instructed that 
their team should focus on learning a specific number of strategic aspects of the task. This instruction was similar to past research (e.g., six strategic learning objectives in Seijts et al., 2004). Participants in prior experimental research (Seijts et al., 2004) did not perceive a difference between specific learning goals and general goals when specific learning goals were operationalized as simply listing a set number of strategies. Thus, we revised our instructions to focus on the content of the learning goal, or learning specific strategic aspects of the task.

Therefore, participants in our specific learning goal condition were told that their team should focus on learning specific strategic aspects of the task, such as how to 1) differentiate their assets, 2) utilize their assets efficiently, 3) monitor enemy and friendly forces, 4) differentiate enemy forces, 5) execute successful attacks, and 6) understand speed and accuracy trade-offs. Thus, instructions were similar to Seijts and colleagues (Seijts et al., 2004) in terms of listing specific learning goals, but more specific in terms of content, which is in line with prior studies of learning that also provided specific learning objectives (Rothkopf \& Billington, 1975, 1979; Rothkopf \& Kaplan, 1972). These specific strategic aspects of the task appropriately focused teams in the specific learning goal condition on learning the behaviors critical to team performance in this task, as well as how to best perform these behaviors.

Because performance goals focus on objective outcomes (e.g., Locke \& Latham, 1990), in the specific performance goal condition, teams were instructed to focus on their performance in the task and given specific offensive and defensive goals (1230 for team offensive points, 41,000 for team defensive points). These goals were derived from a separate sample of prior teams engaged in the same simulation task, and are representative of teams scoring in the $75^{\text {th }}$ to $80^{\text {th }}$ percentiles, which is the typical standard employed in the goal-setting literature (Locke \& 
Latham, 1990). Teams were also told that performing well was valued, expected, and would be rewarded.

To test the success of our manipulation of goal conditions, each team member was asked after the simulation what his or her team's goal was during the simulation. Each team member answered the question by choosing from three options which described the three goal conditions. For example, the specific goal condition was described as a goal to score 1230 on team offense and score 41,000 on team defense. Just over ninety percent of the participants chose the answer that corresponded with the condition to which they were assigned, which resulted in $90.9 \%$ of the teams having 3 or more members who chose the answer that corresponded with the condition to which their team was assigned. We did not exclude the other $9.1 \%$ of teams from the analysis because none of these teams were outliers in our analyses, nor did our results change as a function of dropping these teams. We also measured goal commitment (Hollenbeck, Klein, O’Leary, \& Wright, 1989) after teams received instructions regarding their particular team goals, but before they engaged in the task in order to rule out commitment as an alternative explanation to differences among goal conditions. We found that across all teams the average goal commitment was $3.25(S D=.40)$ on a 5 point scale and the level of goal commitment did not differ significantly across the three goal conditions.

Task Complexity. In each of the goal conditions, teams were randomly assigned to either a simple or a complex task condition. The conditions were later coded such that 0 represented the simple condition, whereas 1 represented the complex condition. According to Wood (1986), task complexity includes component, coordinative, and dynamic complexity. We manipulated task complexity by modifying each of these aspects of the simulation. First, the complex task had a higher number of information cues to process (i.e., enemy and friendly forces), thus enhancing 
its component complexity (Wood, 1986). The complex task also included an unequal workload distribution, in that the nature and number of enemy forces entering a teammate's quadrant exceeded his or her capacity to monitor and disable those forces. Thus, the coordinative complexity of the task was increased (Wood, 1986). Finally, dynamic complexity (Wood, 1986) was created by the introduction of novel enemy forces that were unpredictable in nature, based on the initial training program. Our study represents one of the few studies of learning and performance goals in which task complexity was manipulated (see also Winters \& Latham, 1996).

Team Coordination. Consistent with past research, we measured team coordination using both information exchange and workload adjustment (Moon et al., 2004). Each team member had the option of exchanging (or not) the information about the identity of that force with other team members. Exchanging information required a team member to go through additional effort to request that the information be transferred to other team members. Thus, exchanging this information with other team members demonstrated selflessness on the part of a team member, because the team member sharing the information already knew that information, but was dedicating time and effort to share the information with other team members in order to help the team. Likewise, team members could adjust their actions by helping other team members with their workload. In this task, each team member was responsible for protecting one of four quadrants of the restricted area from enemy forces. The team, however, was collectively responsible for protecting the entire restricted area and the overall team score was based on how well the team as a whole protected that area. Thus, it was in the best interest of the team for team members to adjust and help when other team members experienced uneven workload distribution or lacked the ability to carry out their duties. 
We calculated team coordination as a combination of the total number of times a team member exchanged the information about an enemy or friendly force with his or her team members, as well as the total number of times team members identified and destroyed forces outside of their own geographic region. First, separate z-scores were calculated for the total number of information exchanges as well as for the total number of attacks of enemy forces outside of the assigned quadrant. We then combined the two z-scores, using equal weighting, into an overall measure of team coordination. We also examined the appropriateness of representing team coordination at the team level by examining the intraclass correlation coefficients. The one-way random-effects ANOVA was significant $F(78,237)=1.36(p<.05)$. In addition, the intraclass correlation coefficients of $\operatorname{ICC}(1)=.08$ and $\operatorname{ICC}(2)=.26$ were sufficient to justify aggregation (Bliese, 2000).

Team Performance. Performance on the task included both an accuracy and a speed component. Accuracy on the task was determined by the team's offensive score on the task. Teams started with 1000 offensive points and gained 5 offensive points by successfully disabling enemy forces. If a team cleared an enemy force outside the restricted region or cleared a friendly force, then the team's offensive score dropped by 25 points. Speed on the task was measured by the team's defensive score. The team's defensive score started at 50,000 and decreased 1 or 2 points for every second an enemy was within the restricted region and highly restricted region, respectively. Consistent with past research (Ellis et al., 2003; Hollenbeck, Ellis, Humphrey, Garza, \& Ilgen, 2011, we combined the accuracy and speed components into an overall measure of team performance by first calculating separate z-scores for the team's offensive score and defensive score. We then combined the two z-scores $(r=.28, p<.05)$, using equal weighting, into an overall measure of team performance. 


\section{Analyses}

To test our hypotheses, we used both hierarchical multiple regression and the moderated path analysis framework developed by Edwards and Lambert (2007). Because our hypotheses compared specific learning goals versus general “do your best” learning goals and specific performance goals, we dummy-coded the conditions (see Cohen, Cohen, West, \& Aiken, 2003). In this study, the regression coefficients and significant tests for general “do your best” learning goals compared the mean of general "do your best” learning goals with the mean of specific learning goals. Likewise, the regression coefficients and significant tests for specific performance goals compared the mean of specific performance goals with the mean of specific learning goals. We also centered the measured variables before entering them into the regression and mediated moderation analyses.

\section{Results}

Table 1 presents the means, standard deviations, and zero-order correlations for both the simple and complex task conditions. As the table shows, more team coordination occurred in the complex task $(M=0.51, S D=0.54)$ versus the simple task $(M=-0.53, S D=0.30)$ and team performance suffered in the complex task $(M=-0.50, S D=0.78)$ relative to the simple task $(M=$ $0.52, S D=0.37)$. Team coordination was positively related to team performance in both the simple $(r=.17, n s)$ and complex conditions $(r=.66, p<.01)$. A direct test comparing the correlations found that the correlation in the complex condition was significantly larger $(p<.01)$ than the correlation in the simple condition. We first provide the results for the hypotheses regarding the differential effects of specific learning goals versus general “do your best” learning goals, the moderating role of task complexity on the team process of coordination, and the full mediated moderation model, which hypothesized that team coordination would mediate the 
negative effects of specific learning goals relative to general "do your best” learning goals (Hypotheses 1, 2, and 5). We then provide the results for the hypotheses regarding the differential effects of specific learning goals versus specific performance goals, the moderating role of task complexity on the team process of coordination, and the full mediated moderation model, which hypothesized that team coordination would mediate the negative effects of specific learning goals relative to general “do your best” learning goals (Hypotheses 3, 4, and 6).

In Hypothesis 1 we predicted that teams with specific learning goals would have lower performance relative to teams with general "do your best” learning goals. The first column of Table 2 shows that general "do your best” learning had higher team performance relative to specific learning goals $(\beta=0.34, p<.01)$. Thus, Hypothesis 1 was supported. The bottom of the first column in Table 2 shows that the various types of goals explained $10 \%$ of the variance in team performance $\left(R^{2}=.10, p<.05\right)$

Hypothesis 2 predicted that the negative effect of specific learning goals on team performance relative to general “do your best” learning goals would be mediated by lower team coordination. Hypothesis 5 predicted that the negative effect of specific learning goals on team coordination relative to general "do your best" learning goals would be stronger for teams operating in a complex task. Thus, taken together, these hypotheses represent a first-stage mediated moderation model (Edwards \& Lambert, 2007). Table 3 provides the results of the hierarchical multiple regression analysis in which we assessed moderation of the independent variable on the mediator. The third column of Table 3 shows that the difference in team coordination between specific learning goals and general "do your best” learning goals was a function of task complexity $(\beta=0.27, p<.05)$. More specifically, teams with general "do our best” learning goals had higher levels of team coordination relative to teams with specific 
learning goals in the complex condition. The bottom of the third column in Table 3 shows that the moderation of task complexity on the various types of goals explained an additional five percent of variance in team coordination $\left(\Delta R^{2}=.05, p<.01\right)$

The interaction for team coordination can be seen in Figure 1. In order to interpret the interaction of complexity, we used plotted the interaction using simple slopes analysis by Aiken and West (1991). The high and low levels of the moderator were defined as +1 for the complex condition and 0 for the simple condition. In the complex condition, teams with specific learning goals had lower levels of team coordination relative to teams with general "do your best" learning goals. We also tested for the significance of each slope from zero and found that the slope for general “do your best” learning, as well as the slope for specific learning, were both significantly different from zero at $p<.01$.

In the third column of Table 2, one can also see that the differences in team performance between specific learning goals and general “do your best” learning goals varied as a function of task complexity $(\beta=0.31, p<.05)$. The bottom of Table 2 shows that the combination of the main effect of task complexity and its moderation of the various types of goals explained an additional $44 \%$ of variance in team performance $\left(\Delta R^{2}=.44, p<.01\right)$. The interactions are plotted in Figure 2, where we again used the simple slopes analysis suggested by Aiken and West (1991). In Figure 2 it is clear that the negative effects of specific learning goals on team performance relative to general “do your best” learning goals were particularly pronounced for complex tasks $(p<.05)$. Tests for the significance of each slope differing from zero showed that the slope for general “do your best” learning, as well as the slope for specific learning, were both significantly different from zero at $p<.01$. 
For the final step to test our mediated moderation hypotheses, we used the moderated path analysis framework developed by Edwards and Lambert (2007). We used bootstrap procedures to draw 1000 random samples with replacement from the full sample, and then constructed bias-corrected confidence intervals (Edwards \& Lambert, 2007). Table 4 provides an analysis of the simple effects. Table 4 shows that the indirect effects for the interaction of general “do your best” learning goals (relative to specific learning goals) with complexity on team performance through team coordination were significant. And as Table 4 shows, the moderating effect occurred at the first stage, as predicted. The fourth column of Table 2 shows that team coordination had a positive and significant effect on team performance $(\beta=.55, p<$ $.01)$, and explained an additional 10 percent of the variance in that measure $\left(\Delta R^{2}=.10, p<.01\right)$. Thus, Hypotheses 2 and 5 were supported, in that complexity moderated the negative effect of specific learning goals on team coordination, relative to general “do your best” learning goals, and team coordination mediated the moderated negative effect of specific learning goals on team performance, relative to general “do your best” learning goals.

In Hypothesis 3, we predicted that teams with specific learning goals would perform worse than teams with specific performance goals. The first column of Table 2 shows that specific performance goals indeed led to higher team performance relative to specific learning goals $(\beta=0.26, p<.05)$. Thus, Hypothesis 3 was supported. Hypothesis 4 predicted that the negative effect of specific learning goals on team performance, relative to specific performance goals, would be mediated by lower team coordination. Hypothesis 6 predicted that the negative effect of specific learning goals on team coordination, relative to specific performance goals, would be stronger for team performing a complex task. Thus, these hypotheses represent a firststage mediated moderation model (Edwards \& Lambert, 2007). 
Table 3 provides the results of the hierarchical multiple regression analysis in which we assessed moderation of the independent variable on the mediator. The third column of Table 3 shows that the difference between specific learning goals and specific performance goals was also a function of task complexity $(\beta=0.40, p<.05)$. The interaction for team coordination can be seen in Figure 1, which shows that specific learning goals produced less team coordination ( $p$ $<.05)$ than specific performance goals in the complex condition. The slope of specific performance goals was also significantly different from zero $(p<.01)$.

In the third column of Table 2, one can also see that the differences in team performance between specific learning goals and specific performance goals varied as a function of task complexity $(\beta=0.28, p<.05)$. The interactions are plotted in Figure 2, where we again used simple slopes analysis, as suggested by Aiken and West (1991). In Figure 2, it is clear that the negative effects of specific learning goals (relative to specific performance goals) on team performance were particularly pronounced for complex tasks. A simple slopes analysis found that the slope for specific performance was significantly different from zero $(p<.01)$.

For the final step of our mediated moderation hypotheses, we again used the moderated path analysis framework developed by Edwards and Lambert (2007). Results from the analysis of simple effects can be seen in Table 4. The indirect effects for the interaction of specific performance goals (relative to specific learning goals) with complexity on team performance through team coordination were significant. In addition, Table 4 shows that the moderating effect occurred at the first stage of the model, as predicted. Team coordination had a positive and significant impact on team performance (see Table $2 ; \beta=.55, p<.01$ ). Thus Hypotheses 4 and 6 were supported, in that complexity moderated the negative effect of specific learning goals versus specific performance goals on team coordination, and team coordination mediated the 
moderated negative effect of specific learning goals on team performance versus specific performance goals on team performance.

\section{Discussion}

Our primary interest in this research was to examine whether individual-level research (Seijts et al., 2004) showing the value of specific learning goals generalizes to team contexts. To make this comparison, we examined the influence of three different types of goals on team coordination and performance. To date, goal-setting theory has concluded, based on individuallevel research, that specific learning goals are most effective when a task is complex and requires the acquisition of knowledge, specific learning goals are most effective (Seijts \& Latham, 2005; Seijts et al., 2004). The results of our study show that these findings do not generalize to team contexts. In particular, we found that in teams, the content and degree of specificity in learning goals reduces the value of specific learning goals relative to general “do your best” learning goals and specific performance goals. . The effects of these goals on team performance become even more pronounced in complex tasks, which can be explained by the team process of coordination.

Our findings have important theoretical implications for research on team-level motivation and goal setting. The first implication involves the discontinuity in the influence of specific learning goals on performance between the individual versus the team level of analysis. Many findings from individual-level goal-setting research have generalized to team contexts. For example, beyond the generalization of specific, difficult performance goals to the team context (Kleingeld et al., 2011; O’Leary-Kelly et al., 1994), research has also found that goal setting, effort allocation and regulation, and feedback processes are similar at both the individual-level and team-level (Chen et al., 2009; DeShon, Kozlowski, Schmidt, Milner, \& Wiechmann, 2004; 
Weingart, 1992). Thus, it might be expected that the positive influence of specific learning goals on individual performance would also generalize to team performance. Our findings suggest otherwise, and thus serve as an example of the dangers in generalizing theories across levels of analysis without the necessary empirical support. A second implication of our study involves how different goal types can influence coordination in teams. Our results demonstrate that team coordination can be restricted by specific learning goals relative to general “do your best” learning or specific performance goals. They also demonstrate that restricted coordination due to specific learning goals is particularly detrimental for complex tasks.

\section{Managerial Implications}

An important managerial implication from our study is that managers must recognize the unique features of teams relative to individuals and tailor their goal-setting practices differently for teams. Teams are often formed to deal with complex, novel, and disruptive tasks and environments (Kozlowski \& Bell, 2003; Morgeson, 2005; Morgeson \& DeRue, 2006). The availability of other members to exchange information and support one another with their work enables teams to deal more readily with these complexities, relative to individuals working alone. Coordination is a unique feature of teams that enables teams to achieve higher levels of performance particularly in complex tasks. Thus, it is important for managers to understand how alternative types of goals influence key team processes. Managers should not assume that the same types of goals that work effectively with individuals will also work effectively with teams.

Another implication for managers is that the negative effects of specific learning goals, relative to general “do your best” learning goals and specific performance goals, are particularly pronounced in complex tasks. The effects of task complexity are further heightened by the complexities of interdependence and size in team contexts. When teams perform complex tasks, 
it becomes even more important for team members to exchange information and support one another. Our results indicate that if organizational teams face complex tasks that include large amounts of information and a dynamic environment, then general “do your best” learning goals and specific performance goals will be more effective than specific learning goals. Strengths and Limitations

Several limitations of our study should be noted. First, we chose to define specific learning goals, general “do your best” learning goals, and specific performance goals in ways based on past research (i.e., Rothkopf \& Billington, 1975, 1979; Seijts et al., 2004). However, we recognize the limitations of these operationalizations. For example, specific learning objectives represent only one way in which specific learning goals could be set for teams. Team learning involves more than improvement on individual task knowledge or the pooling of this knowledge (Ellis et al., 2003); it also includes learning new behaviors (DeRue, Hollenbeck, Johnson, Ilgen, \& Jundt, 2008). Thus, specific learning goals for teams could be operationalized according to how much time is spent on learning aspects of the task, brainstorming ideas for performance, or developing shared team mental models. In addition, goal specificity could be described along a continuum from general to specific. Although the current study demonstrates the value of general “do your best” learning goals relative to specific learning goals, caution should be taken in that general “do your best” goals can become too general to sufficiently direct attention to learning. Furthermore, the effects of specificity with regard to learning goals may depend on the amount of learning required, or on how clear it is to management what aspects of the task need to be learned. Future research should investigate alternative operationalizations of general and specific learning goals, especially as they relate to different types of teams, tasks, and learning needs. 
Another limitation of our study is that we focused on team coordination, yet prior research suggests there is a broader range of team processes that can contribute to team performance (LePine, Piccolo, Jackson, Mathieu, \& Saul, 2008; Marks et al., 2001). For example, it is possible that different types of goals influence not only coordination, but also strategy formulation and planning processes, as well as emergent states, such as collective efficacy (DeRue, Hollenbeck, Ilgen, \& Feltz, 2010; Marks et al., 2001; Weldon et al., 1991; Weldon \& Weingart, 1993). A related limitation is our belief that different types of goals narrow the focus of team members, increase perceptions of time pressure, and focus team members on the demonstration versus development of skills. We did not, however, measure these specific changers. Thus, our study represents an initial step in explaining the influence of alternative types of goals on team processes; future research should extend our theory by investigating other team processes and more proximal mediating processes.

Third, our study consisted of ad-hoc teams of undergraduate students working on a military simulation for a short time. Thus, the type of task, the homogenous nature of the sample, and the three-hour fixed time limit are potentially limits to the generalizability of our findings. Participants did, however, work on a realistic team task in which they had to interact, participate, and coordinate in order to achieve their goals. Thus, we believe this task is representative of an interdependent team task and that our study generalizes to short-term project teams whose members work interdependently on novel tasks within a fixed period of time (Devine, 2002; Hollenbeck, Beersma, \& Schouten, 2012). Observation of our participants also suggested that they found the task psychologically engaging and the financial incentives motivating based on their enthusiasm regarding the task and the concerns they expressed about the rewards. Finally, the majority of research on goals has been conducted in the laboratory using various simulations 
(Locke \& Latham, 1990) and the results have been found to generalize to the field (Locke, 1986; Locke \& Latham, 1990). Nevertheless, future research should explore the influence of alternative types of goals on teams in organizational settings across a variety of tasks. This pairing of experimental and field studies would confirm external validity of our findings (Colquitt, 2008). Fourth, our study focused on the comparison of general learning, specific learning, and specific performance goals on team performance. Thus, the study excluded the comparison of general performance goals on team performance, as well as the comparison of all four types of goals on individual performance. The absence of a general performance goal condition is a limitation of the current study, in that we were unable to test the differences among the other three conditions compared to a general performance goal. We chose not to include this condition given the overwhelming evidence from prior research that individuals and teams with specific performance goals outperform those with general performance goals (Kleingeld et al., 2011; Locke \& Latham, 1990; O’Leary-Kelly et al., 1994). Although we cannot compare the relative effects of specific learning goals versus general performance goals, prior research would suggest that general performance goals should result in lower levels of team coordination and performance relative to specific learning goals. Additionally, we did not test the effects of the goal conditions on individual performance, and so we were unable to compare the goal effects across levels of analysis. Given these limitations, future research that compares all four goal types across individual and team levels within a single study would help integrate our findings with prior research.

Finally, our study did not contain a manipulation check for task complexity. We were primarily interested in objective task complexity, as defined by Wood (1986), which emphasizes objective task differences with respect to the number of task elements, the interdependence 
among task elements, and degree to which task elements change. In future research, it might be valuable to explore subjective perceptions of task complexity that arise due to individual differences in skills or self-efficacy, even under conditions when objective task complexity is held constant. We did not measure subjective perceptions of task complexity, and it is possible that within each of the simple and complex conditions there was variance in subjective perceptions of complexity. Future research should investigate the extent to which subjective perceptions of complexity attenuate or accentuate the effects of objective complexity.

Despite these limitations, our study had several strengths. First, our operationalization of goals is consistent with past research (i.e., Rothkopf \& Billington, 1975, 1979; Seijts et al., 2004), which allowed us to investigate whether findings at the individual level generalize to the team level. Second, the laboratory setting allowed us to control for factors that would not be controllable in a field setting. For example, in the laboratory setting, we were able to give each team one goal on which to focus, whereas in a naturalistic setting, it would be more difficult to ensure that each team was assigned a particular goal. Thus, in a laboratory setting it is more likely that teams focused on the goal we set for them and were not balancing between learning and performance goals, which might influence their performance (Bunderson \& Sutcliffe, 2003). Finally, by using the moderated path analysis framework developed by Edwards and Lambert (2007), we were able to test mediation and moderation simultaneously. Thus, we specified a first-stage mediated moderation model, the results of which supported our theory.

\section{Future Research}

The results of our study also point to several areas of future research. First, we examined the extent to which evidence regarding individual goal setting generalizes to team contexts, thereby highlighting the complexities of moving from individual to team level motivation. An 
important area for future research is to examine a multi-level model (Chen \& Kanfer, 2006;

DeShon et al., 2004) in which the influence of alternative goal types is examined simultaneously for both individual and team performance. Examining a multi-level model may reveal cross-level relationships that cannot be detected when focusing solely at the individual or team level (Chen \& Kanfer, 2006).

Second, our study tested one factor (task complexity) among any contextual factors that might influence the goal-performance relationship in teams. Future research needs to extend our study by exploring other aspects of the team context that can influence the goal-performance relationship, such as the level of team member interdependence, team size, goal commitment, and skill level within the team (Latham, 2007; Locke \& Latham, 2004; Weldon \& Weingart, 1993). For example, the level of team interdependence might influence the extent to which team members use processes such as planning to improve coordination in the group (Marks et al., 2001; Weingart \& Weldon, 1991; Weldon \& Weingart, 1993). Likewise, if a team has more skill on the task, then specific learning goals may not decrease team coordination because the team would be better equipped to perform the task.

In our study we also varied all three components of complexity. A potential area of future research would be to examine the moderating influence associated with each component of task complexity separately. For example, dynamic complexity, which relates to the changing nature of the task, may influence the extent to which teams should utilize learning goals versus performance goals because learning goals encourage teams to adapt to the changing nature of the task. In contrast, teams which encounter increased component complexity, or an increased number of information cues to be processed, may need to focus on general “do your best” 
learning goals versus specific learning goals because general “do your best” learning goals promote exchange of information which allows teams to process the additional information cues.

Finally, given that each team in our study had only one goal, another area for future research would be to examine whether or not teams can effectively balance both learning and performance goals. It has been suggested that balancing may occur by alternating learning and performance goals (e.g., Brown \& Eisenhardt, 1998; Gupta, Smith \& Shalley, 2006; Weick, 1976). However, given the fact that specific learning goals narrow the focus of attention, balancing among specific learning goals and other goals may be difficult. Thus, future research should examine whether the balance can be obtained through switching goals or pursuing multiple goals simultaneously. For example, the best team performance may occur when teams are given learning goals in order to learn tasks or develop strategies for the task, and then are switched to a performance goal after they have mastered the task. 


\section{References}

Aiken, L.S., \& West, S.G. (1991). Multiple regression: Testing and interpreting interactions. Newbury Park, CA: Sage.

Beersma, B., Hollenbeck, J.R., Humphrey, S.E., Moon, H., Conlon, D.E., \& Ilgen, D.R. (2003). Cooperation, competition, and team performance: Toward a contingency approach. Academy of Management Journal, 46, 572-590.

Bliese, P.D. (2000). Within-group agreement, non-independence, and reliability: Implications for data aggregation and analysis. In K. J. Klein \& S. W. J. Kozlowski (Eds.), Multilevel theory, research, and methods in organizations: Foundations, extensions, and new directions (pp. 348- 381). San Francisco, CA: Jossey-Bass.

Brown, S.L., \& Eisenhardt, K.M. (1998). Competing on the edge: Strategy as structured chaos. Boston, MA: Harvard Business School Press.

Brown, T.C., \& Latham, G.P. (2002). The effects of behavioural outcome goals, learning goals, and urging people to do their best on an individual's teamwork behaviour in a group problem-solving task. Canadian Journal of Behavioural Science, 34, 276-285.

Bunderson, J.S. \& Sutcliffe, K.M. (2003). Management team learning orientation and business unit performance. Journal of Applied Psychology, 88, 552-560.

Chen, G., \& Kanfer, R. (2006). Toward a systems theory of motivated behavior in work teams. In B. Staw \& L. Cummings (Eds.), Research in organizational behavior (Vol. 27, pp. 223-267). Greenwich, CT: JAI Press.

Chen, G., Kanfer, R., DeShon, R.P., Mathieu, J.E., \& Kozlowski, S.W.J. (2009). The motivating potential of teams: Test and extension of Chen and Kanfer's (2006) cross-level model of 
motivation in teams. Organizational Behavior and Human Decision Processes, 110, 4555.

Cianci, A.M., Klein, H.J., \& Seijts, G.H. (2010). The effect of negative feedback on tension and subsequent performance: The main and interactive effects of goal content and conscientiousness. Journal of Applied Psychology, 95, 618-630.

Cohen, J., Cohen, P., West, S.G., Aiken, L.S. (2003). Applied multiple regression/correlation analysis for the behavioral sciences ( $3^{\text {rd }}$ Ed). Mahwah, NJ: Lawrence Erlbaum Associates.

Colquitt, J.A. (2008). From the editors: Publishing laboratory research in AMJ: A question of when, not if. Academy of Management Journal, 51, 616-620.

DeChurch, L.A., \& Mesmer-Magnus, J.R. (2010). The cognitive underpinnings of effective teamwork: A meta-analysis. Journal of Applied Psychology, 95, 32-53.

DeRue, D.S., Hollenbeck, J.R., Johnson, M.D., Ilgen, D.R., \& Jundt, D.K. (2008). How different team downsizing approaches influence team-level adaptation and performance. Academy of Management Journal, 51, 182-186.

DeRue, D.S., Hollenbeck, J.R., Ilgen, D.R., \& Feltz, D. (2010). Efficacy dispersion in teams: Moving beyond agreement and aggregation. Personnel Psychology, 63, 1-40.

DeShon, R.P., \& Gillespie, J.Z. (2005). A motivated action theory account of goal orientation. Journal of Applied Psychology, 90, 1096-1127.

DeShon, R.P., Kozlowski, S.W.J., Schmidt, A.M., Milner, K.R., \& Wiechmann, D. (2004). A multiple-goal, multilevel model of feedback effects on the regulation of individual and team performance. Journal of Applied Psychology, 89, 1035-1056. 
Devine, D.J. (2002). A review and integration of classification systems relevant to teams in organizations. Group Dynamics - Theory, Research, and Practice, 6, 291-310.

Dweck, C.S. (1986). Motivational processes affecting learning. American Psychologist, 41, 1040-1048.

Edmondson, A. (1999). Psychological safety and learning behavior in work teams. Administrative Science Quarterly, 44, 350-383.

Edwards, J.R., \& Lambert, L.S. (2007). Methods for integrating moderation and mediation: A general analytical framework using moderated path analysis. Psychological Methods, 12, $1-22$.

Ellis, A.P.J., Hollenbeck, J.R., Ilgen, D.R., Porter, C.O.L.H., West, B.J., Moon, H. (2003). Team learning: Collectively connecting the dots. Journal of Applied Psychology, 88, 821-835.

Geen, R. G. (1989). Alternative conceptions of social facilitation. In P. Paulus (Ed.), The psychology of group influence ( $2^{\text {nd }}$ ed., pp. 15-51). Hillsdale, NJ: Erlbaum.

Geen, R.G. (1991). Social motivation. Annual Review of Psychology, 42, 377-399.

Gibson, C., \& Vermeulen, F. (2003). A healthy divide: Subteams as stimulus for team learning behavior. Administrative Science Quarterly, 48, 202-239.

Gupta, A.K., Smith, K.G, \& Shalley, C.E. (2006). The interplay between exploration and exploitation. Academy of Management Journal, 49, 693-708.

Hollenbeck, J.R., Beersma, B., \& Schouten, M.E. (2012). Beyond team types and taxonomies: A dimensional scaling conceptualization for team description. Academy of Management Review, 37, 82-106.

Hollenbeck, J.R., Ellis, A.P.J., Humphrey, S.E., Garza, A.S., \& Ilgen, D.R. (2011). Asymmetry in structural adaptation: The differential impact of centralizing versus decentralizing team 
decision-making structures. Organizational Behavior and Human Decision Processes, 114, 64-74.

Hollenbeck, J.R., Klein, H.J., O’Leary, A.M., \& Wright, P.M. (1989). Investigation of the construct validity of a self-report measure of goal commitment. Journal of Applied Psychology, 74, 951-956.

Hollenbeck, J.R., Moon, H., Ellis, A.P.J., West, B.J., Ilgen, D.R., Sheppard, L., Porter, C.O.L.H., \& Wagner, III., J.A. (2002). Structural contingency theory and individual differences: Examination of external and internal person-team fit. Journal of Applied Psychology, 87, 599-606.

Kanfer, R., \& Ackerman, P. L. (1989). Motivation and cognitive abilities: An integrative/aptitude-treatment interaction approach to skill acquisition. Journal of Applied Psychology, 74, 657-690.

Karau, S.J., \& Kelly, J.R. (1992). The effects of time scarcity and time abundance on teamperformance quality and interaction process. Journal of Experimental Social Psychology, 28, 542-571.

Kelly, J. R., \& Karau, S. J. (1999). Group decision making: The effects of initial preferences and time pressure. Personality and Social Psychology Bulletin, 25, 1342-1354.

Kelly, J.R., \& Loving, T.J. (2004). Time pressure and group performance: Exploring underlying processes in the Attentional Focus Model. Journal of Experimental Social Psychology, 40, 185-198.

Kleingeld, A., van Mierlo, H., \& Arends, L. (2011). The effect of goal setting on group performance: A meta-analysis. Journal of Applied Psychology, 96, 1289-1304. 
Kozlowski, S.W.J., \& Bell, B.S. (2003). Work groups and teams in organizations. In W. C. Borman, D. R. Ilgen, \& R. J. Klimoski (Eds.), Handbook of psychology, industrial and organizational psychology (Vol. 12, pp. 333-375). Hoboken, NJ: John Wiley \& Sons.

Kozlowski, S.W.J., \& Bell, B.S. (2006). Disentangling achievement orientation and goal setting: effects on self-regulatory processes. Journal of Applied Psychology, 91, 900-916.

Latham, G.P. (2007). Work motivation: History, theory, research, and practice. Thousand Oaks, CA: Sage Publications.

Latham, G.P., \& Locke, E.A. (2007). New developments in and directions for goal-setting research. European Psychologist, 12, 290-300.

LePine, J.A., Piccolo, R.F., Jackson, C.L., Mathieu, J.E., \& Saul, J.R. (2008). A meta-analysis of teamwork processes: Tests of a multidimensional model and relationships with team effectiveness criteria. Personnel Psychology, 61, 273-307.

Locke, E.A. (1986). Generalizing from laboratory to field settings. Lexington, MA: Lexington Books.

Locke, E. A., \& Latham, G. P. (1990). A theory of goal setting and task performance. Englewood Cliffs, NJ: Prentice-Hall.

Locke, E. A., \& Latham, G. P. (2002). Building a practically useful theory of goal setting and task motivation: A 35-year odyssey. American Psychologist, 57, 705-717.

Marks, M.A., Mathieu, J.E., \& Zaccaro, S.J. (2001). A temporally based framework and taxonomy of team processes. Academy of Management Review, 26, 356-376.

Mitchell, T.R., \& Daniels, D. (2003). Motivation. In W. C. Borman, D. R. Ilgen, \& R. J. Klimoski (Eds.), Handbook of psychology, industrial and organizational psychology (Vol. 12, pp. 225-254). Hoboken, NJ: John Wiley \& Sons. 
Moon, H., Hollenbeck, J.R., Humphrey, S.E., Ilgen, D.R., West, B., Ellis, A.P.J., \& Porter, C.O.L.H. (2004). Asymmetric adaptability: Dynamic team structures as one-way streets. Academy of Management Journal, 47, 681-695.

Moreland, R. L. (1999). Transactive memory: Learning who knows what in work groups and organizations. In L. Thompson, D. Messick, \& J. Levine (Eds.). Shared cognition in organizations: The management of knowledge (pp. 3-31). Hillsdale, NJ: Erlbaum.

Morgeson, F.P. (2005). The external leadership of self-managing teams: Intervening in the context of novel and disruptive events. Journal of Applied Psychology, 90, 497-508.

Morgeson, F. P., \& DeRue, D. S. (2006). Event criticality, urgency, and duration: Understanding how events disrupt teams and influence team leader intervention. Leadership Quarterly, $17,271-287$.

Nissen, M. J., \& Bullemer, P. (1987). Attentional requirements of learning: Evidence from performance measures. Cognitive Psychology, 19, 1-32.

O'Leary-Kelly, A.M., Martocchio, J.J., \& Frink, D.D. (1994). A review of the influence of team goals on team performance. Academy of Management Journal, 37, 1285-1301.

Rothkopf, E.Z., \& Billington, M.J. (1975). A two-factor model on the effect of goal-descriptive direction on learning from text. Journal of Educational Psychology, 67, 692-704.

Rothkopf, E.Z., \& Billington, M.J. (1979). Goal-guided learning from test: Inferring a descriptive processing model from inspection times and eye movements. Journal of Educational Psychology, 71, 310-327.

Rothkopf, E.Z., \& Kaplan, R. (1972). Exploration of the effect of density and specificity of instructional objectives on learning from text. Journal of Educational Psychology, 63, 295-302. 
Seijts, G.H., \& Latham, G.P. (2005). Learning versus performance goals: When should each be used? Academy of Management Executive, 19, 124-131.

Seijts, G.H., Latham, G.P., Tasa, K., \& Latham, B.W. (2004). Goal setting and goal orientation: An integration of two different yet related literatures. Academy of Management Journal, 47, 227-239.

Weick, K.E. (1976). Organizations as loosely coupled systems. Administrative Science Quarterly, 21, 1-19.

Weingart, L.R. (1992). Impact of group goals, task component complexity, effort, and planning on group-performance. Journal of Applied Psychology, 77, 682-693.

Weingart, L.R., \& Weldon, E. (1991). Processes that mediate the relationship between a group goal and group member performance. Human Performance, 4, 33-54.

Weldon, E., \& Weingart, L.R. (1993). Group goals and group performance. British Journal of Social Psychology, 32, 307-334.

Weldon, E., Jehn, K.M., \& Pradhan, P. (1991). Processes that mediate the relationship between a group goal and improved group performance. Journal of Personality and Social Psychology, 61, 555-569.

Winters, D., \& Latham, G. P. (1996). The effect of learning versus outcome goals on a simple versus a complex task. Team and Organization Management, 21, 235-250.

Wittenbaum, G.M., Vaughan, S.I., \& Stasser, G. (1998). Coordination in task-performing groups. In R. S. Tindale, J. Edwards, E. J. Posavac, et al. (Eds.), Social psychological applications to social issues: Applications of theory and research on groups (pp. 177204). New York: Plenum Press. 
Wood, R. E. (1986). Task complexity: Definition of the construct. Organizational Behavior and Human Decision Processes, 37, 60-82.

Wood, R., \& Locke, E. (1990). Goal setting and strategy effects on complex tasks. In B. Staw \& L. Cummings (Eds.), Research in organizational behavior (Vol. 12, pp. 73-109). Greenwich, CT: JAI Press.

Wood, R., Mento, A. J., \& Locke, E. A. (1987). Task complexity as a moderator of goal effects: A meta-analysis. Journal of Applied Psychology, 72, 416-425. 